\title{
Tobacco smoking and the risk of sudden cardiac death: a systematic review and meta-analysis of prospective studies
}

\author{
Dagfinn Aune ${ }^{1,2,3}$ (1) $\cdot$ Sabrina Schlesinger ${ }^{4} \cdot$ Teresa Norat $^{1} \cdot$ Elio Riboli $^{1}$
}

Received: 10 August 2017 / Accepted: 22 December 2017 / Published online: 7 February 2018

(C) The Author(s) 2018. This article is an open access publication

\begin{abstract}
Smoking is an established risk factor for cardiovascular disease including coronary heart disease and stroke, however, data regarding smoking and sudden cardiac death have not been summarized in a meta-analysis previously. We therefore conducted a systematic review and meta-analysis to clarify this association. We searched the PubMed and Embase databases for studies of smoking and sudden cardiac death up to July 20th 2017. Prospective studies were included if they reported adjusted relative risk (RR) estimates and 95\% confidence intervals (CIs) for smoking and sudden cardiac death. Summary RRs were estimated by use of a random effects model. Twelve prospective studies were included. The summary RR was 3.06 (95\% CI 2.46-3.82, $\mathrm{I}^{2}=41 \%$, pheterogeneity $=0.12, \mathrm{n}=7$ ) for current smokers and 1.38 (95\% CI $1.20-1.60$, $\mathrm{I}^{2}=0 \%$, pheterogeneity $=0.55, \mathrm{n}=7$ ) for former smokers compared to never smokers. For four studies using non-current (never + former) smokers as the reference category the summary RR among current smokers was 2.08 (95\% CI 1.70-2.53, $\mathrm{I}^{2}=18 \%$, pheterogeneity $=0.30$ ). The results persisted in most of the subgroup analyses. There was no evidence of publication bias. These results confirm that smoking increases the risk of sudden cardiac death. Any further studies should investigate in more detail the effects of duration of smoking, number of cigarettes per day, pack-years, and time since quitting smoking and sudden cardiac death.
\end{abstract}

Keywords Smoking $\cdot$ Sudden cardiac death $\cdot$ Systematic review $\cdot$ Meta-analysis

\section{Introduction}

Cardiovascular disease is the leading cause of death globally, accounting for 17.9 million deaths worldwide in 2015 [1]. It has been estimated that approximately $40-50 \%$ of all

Electronic supplementary material The online version of this article (https://doi.org/10.1007/s10654-017-0351-y) contains supplementary material, which is available to authorized users.

Dagfinn Aune

d.aune@imperial.ac.uk

1 Department of Epidemiology and Biostatistics, School of Public Health, Imperial College London, St. Mary's Campus, Norfolk Place, Paddington, London W2 1PG, UK

2 Bjørknes University College, Oslo, Norway

3 Department of Endocrinology, Morbid Obesity and Preventive Medicine, Oslo University Hospital, Oslo, Norway

4 Institute for Biometrics and Epidemiology, German Diabetes Center (DDZ) at Heinrich Heine University Düsseldorf, Düsseldorf, Germany cardiovascular deaths are sudden cardiac deaths and about $80 \%$ of these are ventricular tachyarrhythmias [2]. In the US approximately 250 000-310 000 sudden cardiac deaths occur annually $[3,4]$. Sudden cardiac death is defined as an unexpected, pulseless condition attributable to a cardiac arrhythmia [5], and most cardiac arrests present without warning symptoms and are usually fatal $[6,7]$. Preventive efforts have focused on using cardioverter-defibrillators in the highest risk groups such as patients with advanced cardiomyopathy and reduced left ventricular ejection fraction [8], however, these high risk groups only account for $25-30 \%$ of all sudden cardiac deaths and the majority occur in the general population and in persons without established coronary heart disease $[9,10]$. Population-wide strategies for primary prevention may therefore be a more promising approach to reduce the incidence of sudden cardiac deaths.

Established or suspected risk factors for sudden cardiac death include age, obesity, diabetes, physical inactivity, dietary factors, hypertension, high serum cholesterol, high resting heart rate and family history of sudden cardiac death [11-13]. A number of cohort studies have also reported a 
strong increase in the risk of sudden cardiac death among smokers [13-23], however, the strength of the associations reported have varied from a $50 \%$ increase in risk to 5.5-fold increases in risk [13-23]. Differences in effect sizes may be due to differences in; the sample sizes, duration of follow-up, geographic location, or the definition of the reference group (e.g. never smokers vs. non-current smokers) between studies and/or chance variation. To our knowledge there has not been published a meta-analysis on smoking and sudden cardiac death previously. For these reasons we conducted a systematic review and meta-analysis of published prospective studies on smoking and risk of sudden cardiac death. Specifically we aimed to clarify the strength of the association, the shape of the dose-response relationship, the effects of quitting smoking and potential sources of heterogeneity in subgroup and sensitivity analyses.

\section{Materials and methods}

\section{Search strategy and inclusion criteria}

We searched the Pubmed, and Embase databases from their inception up to July 20th 2017 for eligible studies (DA, SS). The search terms used are shown in Supplementary Table 1 and 2. We followed standard criteria (Moose criteria) for reporting meta-analyses [24]. In addition, we searched the reference lists of the identified publications for further studies. Study quality was assessed using the Newcastle-Ottawa scale which rates studies according to selection, comparability and outcome assessment with a score range from 0 to 9 [25].

\section{Study selection}

Eligible studies for inclusion in the meta-analysis included published retrospective and prospective cohort studies and nested case-control studies within cohorts that investigated the association between smoking and sudden cardiac death. Adjusted estimates of the relative risk (RR) had to be available with the $95 \%$ confidence intervals (CIs) in the publication. No language restrictions were employed in the search or study selection. A list of the excluded studies can be found in Supplementary Table 3.

\section{Data extraction}

The following data were extracted from each study: The first author's last name, publication year, country where the study was conducted, study period, sample size, number of cases and participants, subgroup, relative risks and $95 \%$ confidence intervals for smokers versus nonsmokers and variables adjusted for in the analysis. DA conducted the data extraction and it was checked for accuracy by SS. Any disagreements between the authors were resolved by discussion.

\section{Statistical methods}

We calculated summary RRs and 95\% CIs of sudden cardiac death comparing current, former and ever smokers with never smokers using the random-effects model by DerSimonian and Laird [26] which takes into account both within and between study variation (heterogeneity). The average of the natural logarithm of the relative risks was estimated and the relative risk from each study was weighted using random effects weights. Studies that used non-current smokers (never + former smokers) as the reference category were analyzed separately to keep the reference category as clean as possible as there is evidence of increased risk also among former smokers. For studies that did not report results for ever smokers we pooled the RRs (95\% CIs) for current and former smokers using a fixed-effects model to obtain risk estimates for ever smokers.

Heterogeneity between studies was evaluated using Q and $\mathrm{I}^{2}$ statistics [27]. $\mathrm{I}^{2}$ is a measure of how much of the heterogeneity that is due to between study variation rather than chance. $\mathrm{I}^{2}$-values of 25,50 and $75 \%$ indicates low, moderate and high heterogeneity respectively. We conducted main analyses (all studies combined) and stratified by study characteristics such as sex, sample size, number of cases, geographic location, study quality and by adjustment for confounding factors (age, family history of coronary heart disease, alcohol, BMI, diabetes, hypertension, high cholesterol, prevalent coronary heart disease, use of QT prolonging drugs, use of digoxin, and physical activity) to investigate potential sources of heterogeneity.

Publication bias was assessed using Egger's test [28] and Begg-Mazumdar's test [29] and by inspection of funnel plots. The statistical analyses were conducted using the software package Stata, version 13.1 software (StataCorp, Texas, US).

\section{Results}

We identified a total of 12 cohort studies (11 publications) [13-23] that were included in the meta-analysis (Fig. 1, Table 1). Nine of the studies were from Europe, three were from the USA, and one was from Japan. Seven studies (four publications) [14, 16-18] were included in the analysis of current, former, and ever smokers versus never smokers and risk of sudden cardiac death and included 1055 sudden cardiac deaths and 138273 participants. One publication included results from four different cohort 


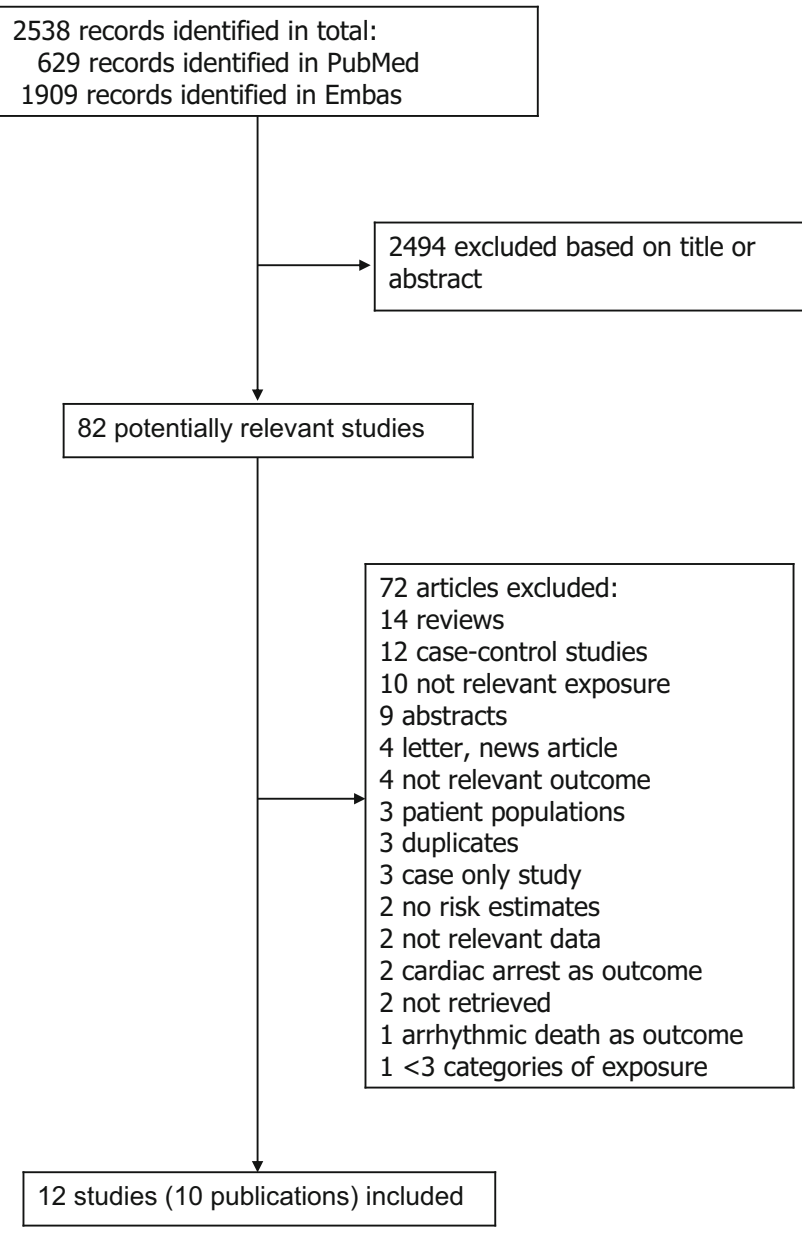

Fig. 1 Flow-chart of study selection

studies [18]. The summary relative risk for current smokers versus never smokers was 3.06 (95\% CIs 2.46-3.82, $\left.\mathrm{I}^{2}=40.5 \%, \quad p_{\text {heterogeneity }}=0.12, \quad \mathrm{n}=7\right) \quad$ (Fig. 2a) [14, 16-18], for former smokers it was $1.38(95 \% \mathrm{CI}$ $1.20-1.60, \mathrm{I}^{2}=0 \%$, pheterogeneity $=0.55, \mathrm{n}=7$ ) (Fig. $2 \mathrm{~b}$ ) [14, 16-18], and for ever smokers it was 2.01 (95\% CI $1.70-2.38, \quad \mathrm{I}^{2}=54.1 \%, \quad$ pheterogeneity $=0.04, \quad \mathrm{n}=7$ ) (Fig. 2c) [14, 16-18]. There was no evidence of publication bias with Egger's test or with Begg's test (Supplementary Fig. 1) for current smokers $(p=0.12$ and $p=0.14$, respectively), former smokers $(p=0.85$ and 0.24 , respectively) or for ever smokers ( $p=0.11$ and 0.14 , respectively). Among four studies [20-23] (1061 cases, 181,679 participants) that analyzed the association between current smoking and sudden cardiac death using non-current (never + former) smokers as the reference category the summary RR was $2.08 \quad(95 \%$ CI: $1.70-2.53$, $\mathrm{I}^{2}=17.5 \%$, pheterogeneity $\left.=0.30\right)($ Fig. $2 \mathrm{~d})$.

Only two studies $[13,17]$ were included in the doseresponse analysis and included 469 sudden cardiac deaths and 108,764 participants. The summary RR per 10 cigarettes per day was $1.58 \quad\left(1.39-1.79, \quad \mathrm{I}^{2}=0 \%\right.$, pheterogeneity $=0.46)($ Fig. 3). Nonlinear analyses were not possible because only one of the studies [17] reported categorical data.

\section{Subgroup and sensitivity analyses and study quality}

There were positive associations in all subgroup analyses, defined by duration of follow-up, sex, geographic location, number of cases, study quality and adjustment for confounding factors (including age, family history of coronary heart disease, alcohol, BMI, diabetes, hypertension, high cholesterol, prevalent coronary heart disease, use of QT prolonging drugs, use of digoxin, and physical activity) (Table 2). With meta-regression analyses there was little evidence that the results differed between these subgroups. Only in the subgroup analysis stratified by duration of follow-up among ever versus never smokers was there between-subgroup heterogeneity, $p_{\text {heterogeneity }}=0.04$, with a stronger association among studies with a shorter compared to a longer duration of follow-up $(2.57,95 \% \mathrm{CI}$ : $1.80-3.68$ vs. $1.78,95 \%$ CI $1.58-2.01$, respectively).

The association between smoking status and sudden cardiac death was robust in sensitivity analyses excluding one study at a time (Supplementary Fig. 1-3).

The mean (median) study quality scores were 8.0 (7.3) for the seven studies included in the analysis of smoking status and sudden cardiac death (Supplementary Table 4). There was no evidence of heterogeneity between subgroups when stratified by study quality scores.

\section{Discussion}

To our knowledge, this is the first meta-analysis that summarize data on smoking status and risk of sudden cardiac death. There was a threefold increase in the risk of sudden cardiac death among current smokers, a 38\% increase in the relative risk among former smokers and a twofold increase in the risk among ever smokers compared to never smokers. In a separate analysis of studies that compared current smokers with non-current (never + former) smokers there was a twofold increase in the risk. This is consistent with the main analysis as inclusion of former smokers together with never smokers would have contaminated the reference group and led to an underestimation of the true association between smoking and sudden cardiac death. There was a 58\% increase in the relative risk per 10 cigarettes per day, however, only two studies were included in the dose-response analysis. The positive associations were observed across geographic location and sex, although the number of studies in some subgroups was modest. 


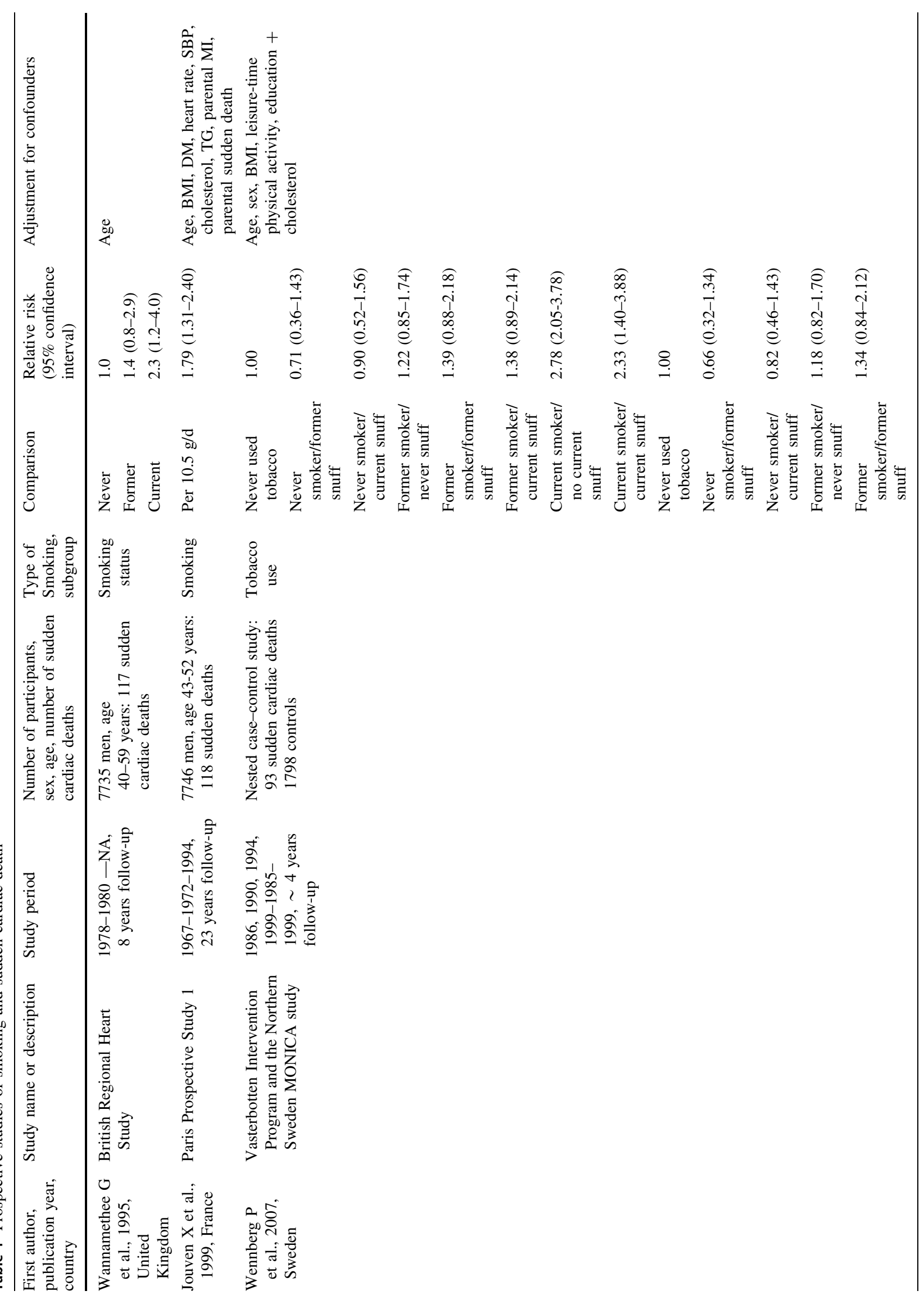




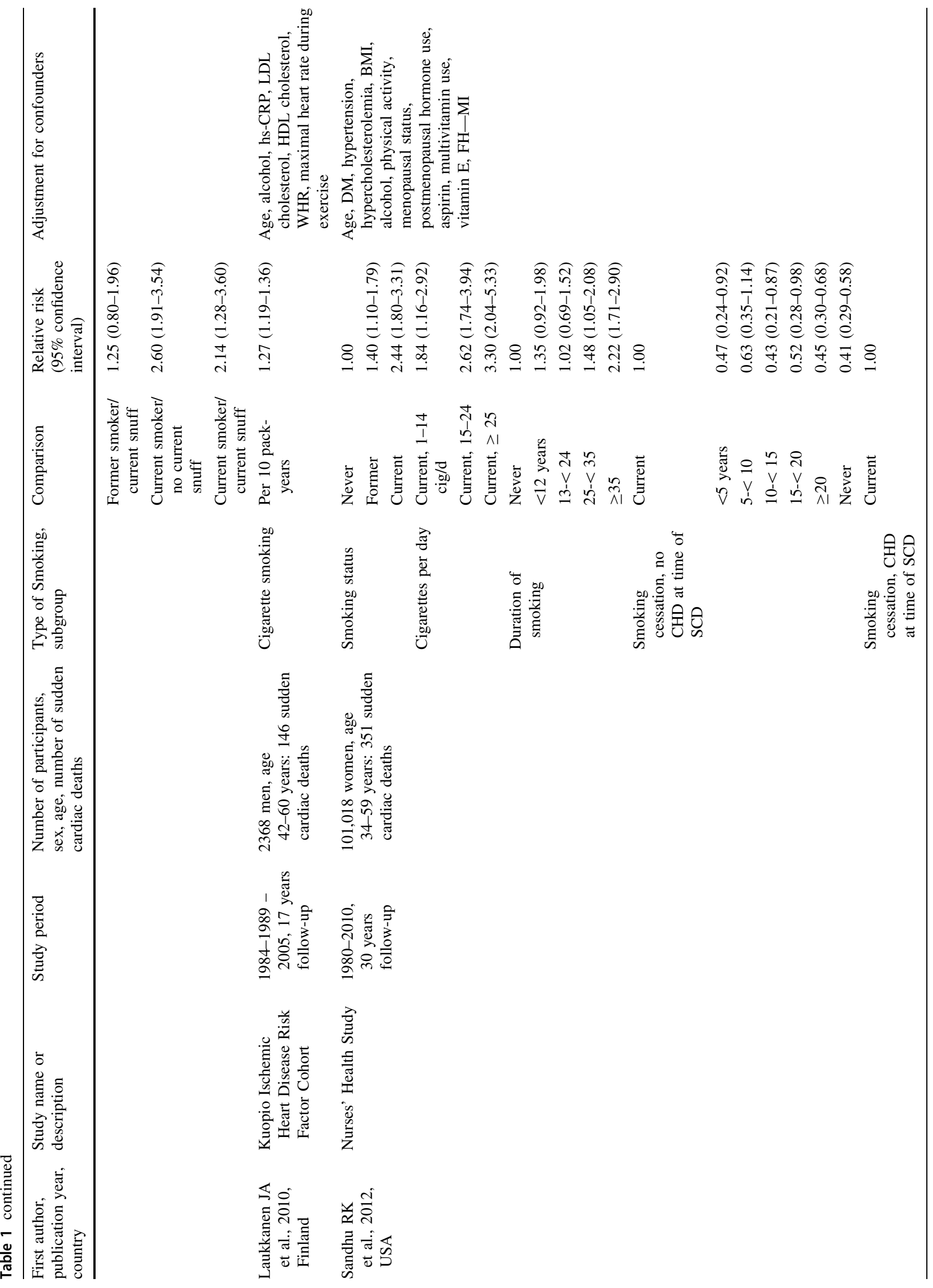




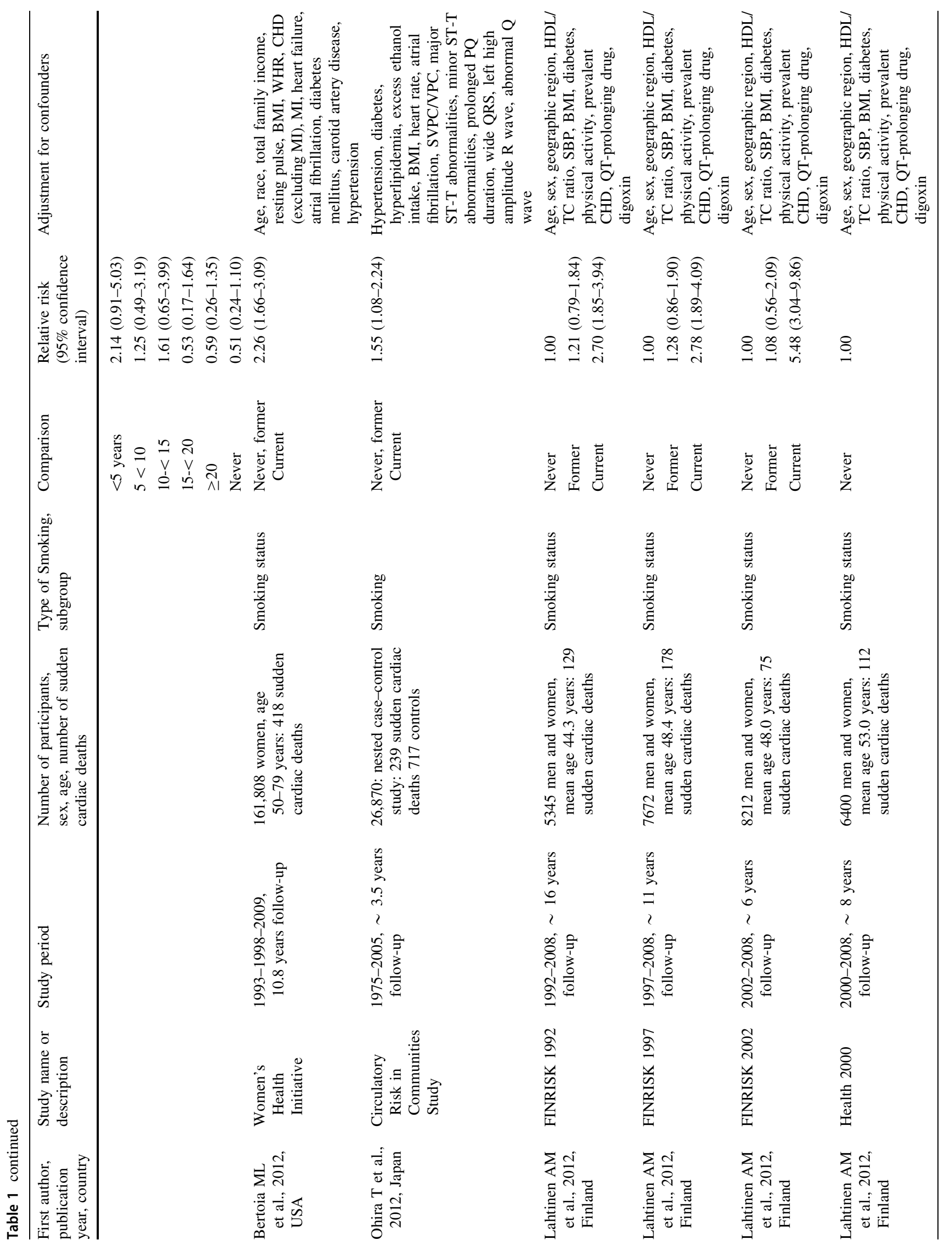




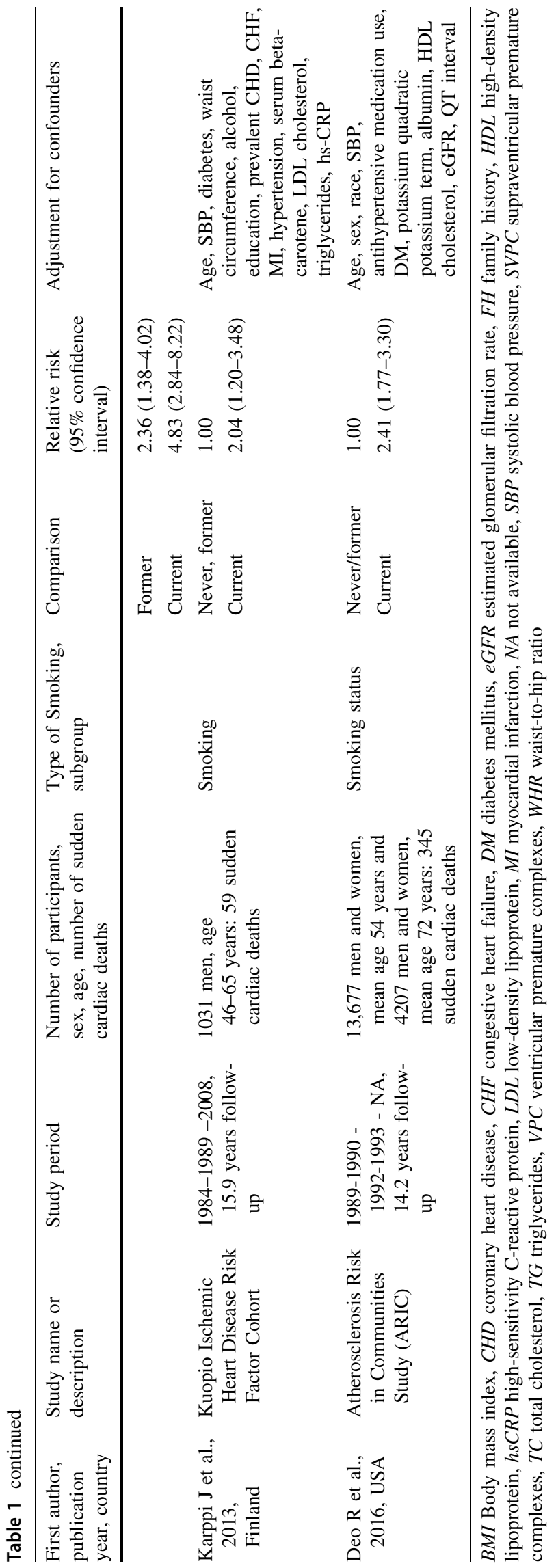

The present systematic review and meta-analysis has some limitations that need to be discussed. Smokers often have less healthy lifestyles than persons never smokers, including more abdominal adiposity, less physically activity, and unhealthy diets. Some of the included studies adjusted for the most important confounding factors and the results persisted across all these subgroup analyses, and we found little evidence of heterogeneity between these subgroups. Only in the subgroup analysis stratified by duration of follow-up was there significant heterogeneity, and there was a weaker association among studies with a longer duration of follow-up compared to studies with a shorter duration of follow-up, although it's unclear if this simply was a chance finding because of the many subgroup analyses that were conducted or if it could indicate some degree of regression dilution bias with misclassification of smoking exposure over time (for example if some of the smokers quit smoking during follow-up). Although the possibility that residual confounding partly could explain the results cannot be entirely excluded we consider this less likely as smoking appears to be one of the strongest risk factors for sudden cardiac deaths. Smoking was assessed by self-report, however, most studies have found a high correlation between self-reported smoking habits and biological markers of tobacco use [30] as well as strong associations with chronic disease outcomes [31]. Given the prospective study design any measurement errors or regression dilution bias would most likely have tended to lead to an underestimation of the association between smoking and sudden cardiac death. Although there was moderate heterogeneity in some of the analyses this appeared to the driven more by differences in the strength of the association than by differences in the direction of the association as all the studies found risk estimates in the direction of increased risk. Finally, few studies had investigated number of cigarettes and the duration of smoking cessation in relation to risk of sudden cardiac death, and any further studies should therefore aim to clarify the dose-response relationship between increasing number of cigarettes, duration of smoking or pack-years as well as the duration of smoking cessation and risk of sudden cardiac death.

The observed associations with a dose-response relationship between increasing number of cigarettes per day and increased risk of sudden cardiac death as well as a reduced risk of sudden cardiac deaths among former smokers compared to current smokers suggests an underlying biological relationship and several biological mechanisms could explain the observed associations. Approximately $80 \%$ of sudden cardiac deaths are ventricular tachyarrhythmias [2] and smokers have been found to be at increased risk of incident and recurrent ventricular tachyarrhythmias or ventricular fibrillation [32-34], which 

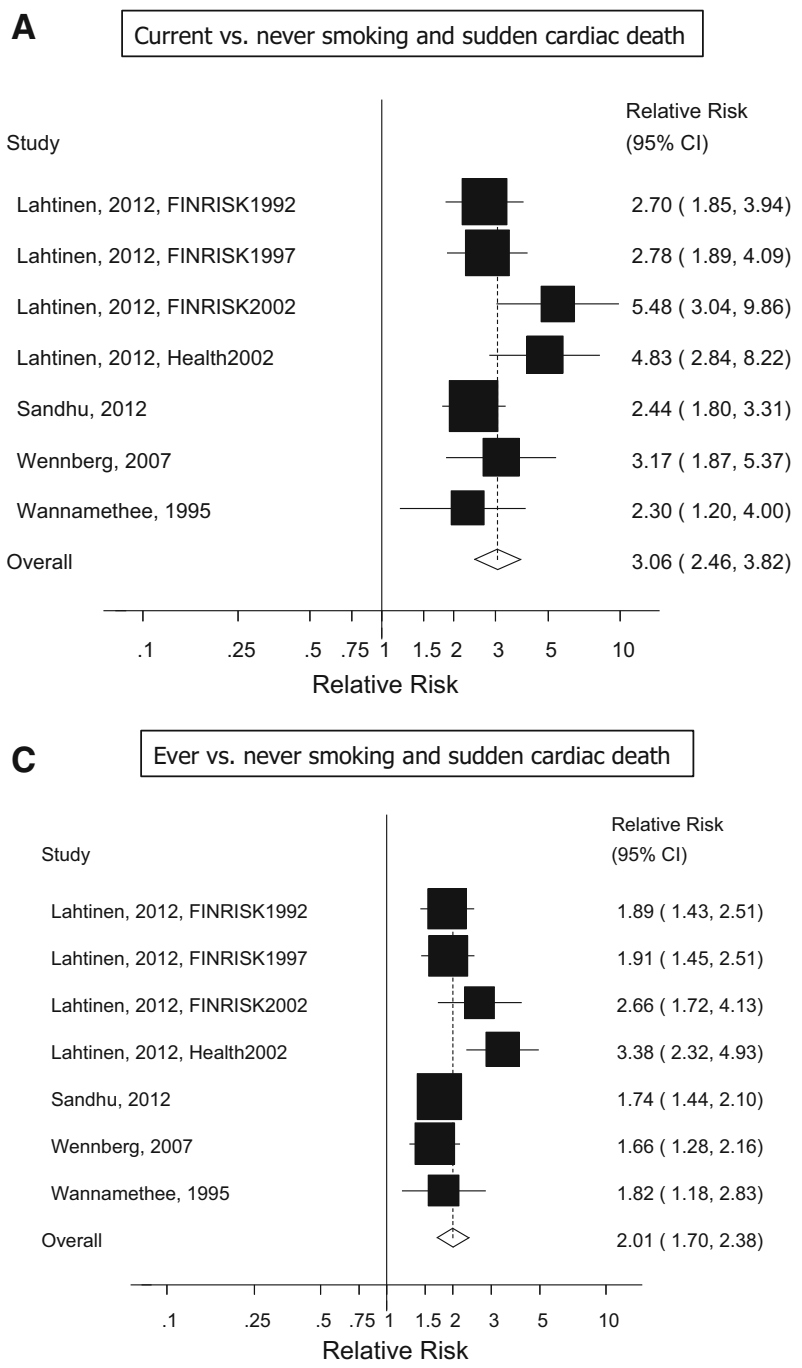

Fig. 2 Smoking status and sudden cardiac death

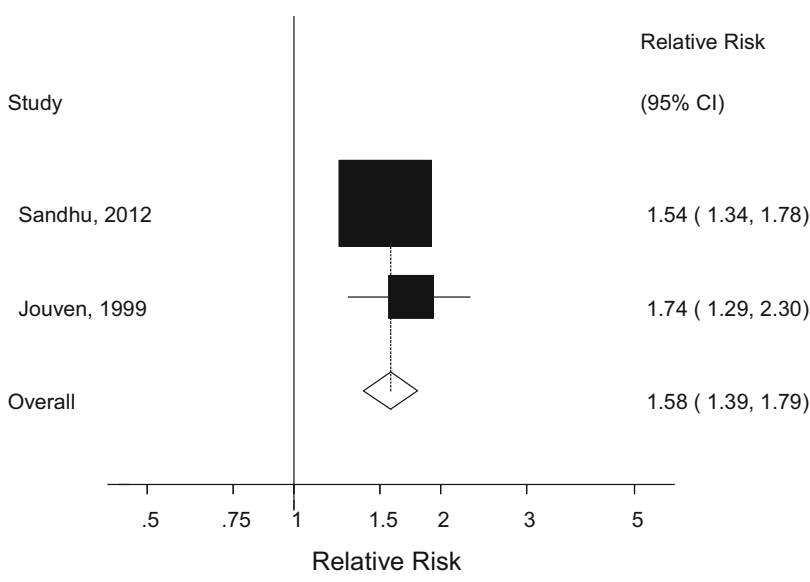

Fig. 3 Cigarettes per day and sudden cardiac death, per 10 cigarettes per day

may be explained by altered ventricular recovery time dispersion indices [35]. Nicotine, which is one of the
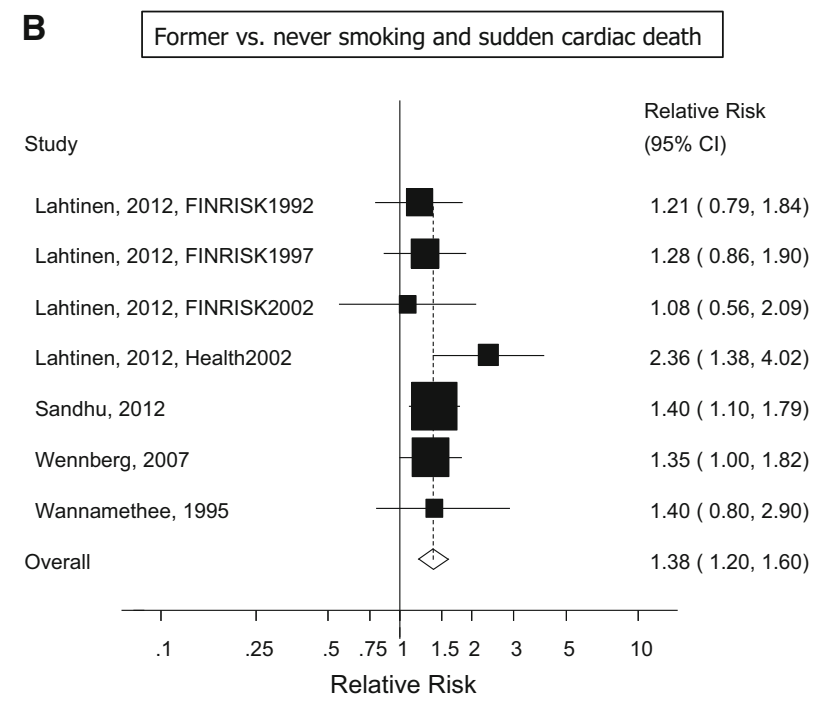

D Current smoking vs. non-current smoking and sudden cardiac death

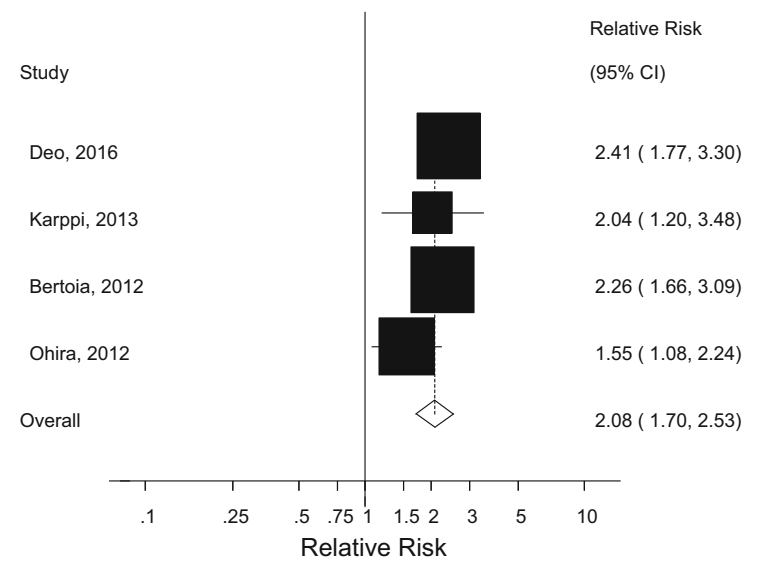

constituents of cigarettes, has been shown to induce a wide range of cardiac arrhythmias in animal studies, including transient sinus arrest, bradycardia, sinus tachychardia, atrial fibrillation, sinoatrial block, atrioventricular block and ventricular tachyarrhythmia [36]. Epidemiological studies have also found that smoking increases the risk of atrial fibrillation [37], which is a strong risk factor for sudden cardiac death [38]. Studies have also found that smoking increases blood pressure, resting heart rate and risk of type 2 diabetes [39-43], risk factors that have been associated with increased risk of sudden cardiac death $[11,13]$.

The present meta-analysis also has some strengths including the prospective design of the included studies (which avoids recall bias and reduces the potential for selection bias), the detailed subgroup and sensitivity analyses, the high study quality, and the increased sample size providing a more robust estimate of the association 
Table 2 Subgroup analyses of smoking status and sudden cardiac death

\begin{tabular}{|c|c|c|c|c|c|c|c|c|c|c|}
\hline & \multicolumn{5}{|c|}{ Current Smoking } & \multicolumn{5}{|c|}{ Former smoking } \\
\hline & $n$ & RR $(95 \% \mathrm{CI})$ & $I^{2}(\%)$ & $P_{\mathrm{h}}^{1}$ & $P_{\mathrm{h}}^{2}$ & $n$ & $\mathrm{RR}(95 \% \mathrm{CI})$ & $I^{2}(\%)$ & $P_{\mathrm{h}}^{1}$ & $P_{\mathrm{h}}^{2}$ \\
\hline All studies & 7 & $3.06(2.46-3.82)$ & 40.5 & 0.12 & & 7 & $1.38(1.20-1.60)$ & 0 & 0.55 & \\
\hline \multicolumn{11}{|l|}{ Follow-up } \\
\hline$<10$ years & 3 & $3.97(2.37-6.64)$ & 58.6 & 0.09 & 0.10 & 3 & $1.58(0.99-2.53)$ & 43.8 & 0.17 & 0.37 \\
\hline$\geq 10$ years & 4 & $2.67(2.21-3.22)$ & 0 & 0.85 & & 4 & $1.34(1.14-1.57)$ & 0 & 0.94 & \\
\hline \multicolumn{11}{|l|}{ Sex } \\
\hline Men & 1 & $2.30(1.20-4.00)$ & & & 0.20 & 1 & $1.40(0.80-2.90)$ & & & 0.91 \\
\hline Women & 1 & $2.44(1.80-3.31)$ & & & & 1 & $1.40(1.10-1.79)$ & & & \\
\hline Men and women & 5 & $3.44(2.62-4.51)$ & 40.2 & 0.15 & & 5 & $1.38(1.12-1.71)$ & 18.9 & 0.30 & \\
\hline \multicolumn{11}{|c|}{ Geographic location } \\
\hline Europe & 6 & $3.26(2.54-4.20)$ & 37.2 & 0.16 & 0.35 & 6 & $1.38(1.15-1.64)$ & 0 & 0.42 & 0.91 \\
\hline America & 1 & $2.44(1.80-3.31)$ & & & & 1 & $1.40(1.10-1.79)$ & & & \\
\hline Asia & 0 & & & & & 0 & & & & \\
\hline \multicolumn{11}{|l|}{ Number of cases } \\
\hline$<100$ & 2 & $4.10(2.40-7.01)$ & 45.8 & 0.18 & 0.15 & 2 & $1.30(0.99-1.71)$ & 0 & 0.55 & 0.86 \\
\hline $100-<150$ & 3 & $3.10(2.05-4.67)$ & 51.4 & 0.13 & & 3 & $1.56(1.03-2.38)$ & 47.1 & 0.15 & \\
\hline$\geq 150$ & 2 & $2.57(2.02-3.26)$ & 0 & 0.60 & & 2 & $1.37(1.11-1.68)$ & 0 & 0.71 & \\
\hline \multicolumn{11}{|l|}{ Study quality } \\
\hline $0-3$ stars & 0 & & & & 0.18 & 0 & & & & 0.90 \\
\hline 4-6 stars & 2 & $2.41(1.84-3.16)$ & 0 & 0.86 & & 2 & $1.40(1.11-1.76)$ & 0 & 0.99 & \\
\hline $7-9$ stars & 5 & $3.44(2.62-4.51)$ & 40.2 & 0.15 & & 5 & $1.38(1.12-1.71)$ & 18.9 & 0.30 & \\
\hline \multicolumn{11}{|c|}{ Adjustment for confounding factors } \\
\hline \multicolumn{11}{|c|}{ Age } \\
\hline Yes & 7 & $3.06(2.46-3.82)$ & 40.5 & 0.12 & NC & 7 & $1.38(1.20-1.60)$ & 0 & 0.55 & $\mathrm{NC}$ \\
\hline No & 0 & & & & & 0 & & & & \\
\hline \multicolumn{11}{|c|}{ Family history of $C H D$} \\
\hline Yes & 1 & $2.44(1.80-3.31)$ & & & 0.35 & 1 & $1.40(1.10-1.79)$ & & & 0.91 \\
\hline No & 6 & $3.26(2.54-4.20)$ & 37.2 & 0.16 & & 6 & $1.38(1.15-1.64)$ & 0 & 0.42 & \\
\hline \multicolumn{11}{|l|}{ Alcohol } \\
\hline Yes & 1 & $2.44(1.80-3.31)$ & & & 0.35 & 1 & $1.40(1.10-1.79)$ & & & 0.91 \\
\hline No & 6 & $3.26(2.54-4.20)$ & 37.2 & 0.16 & & 6 & $1.38(1.15-1.64)$ & 0 & 0.42 & \\
\hline \multicolumn{11}{|l|}{$B M I$} \\
\hline Yes & 6 & $3.18(2.49-4.05)$ & 46.6 & 0.10 & 0.46 & 6 & $1.38(1.19-1.60)$ & 0 & 0.42 & 0.97 \\
\hline No & 1 & $2.30(1.20-4.00)$ & & & & 1 & $1.40(0.80-2.90)$ & & & \\
\hline \multicolumn{11}{|l|}{ Diabetes } \\
\hline Yes & 5 & $3.22(2.42-4.28)$ & 57.1 & 0.05 & 0.62 & 5 & $1.40(1.14-1.70)$ & 18.6 & 0.30 & 0.88 \\
\hline No & 2 & $2.76(1.85-4.10)$ & 0 & 0.43 & & 2 & $1.36(1.04-1.78)$ & 0 & 0.92 & \\
\hline \multicolumn{11}{|l|}{ Hypertension } \\
\hline Yes & 1 & $2.44(1.80-3.31)$ & & & 0.35 & 1 & $1.40(1.10-1.79)$ & & & 0.91 \\
\hline No & 6 & $3.26(2.54-4.20)$ & 37.2 & 0.16 & & 6 & $1.38(1.15-1.64)$ & 0 & 0.42 & \\
\hline \multicolumn{11}{|l|}{ Blood cholesterol } \\
\hline Yes & 5 & $3.22(2.42-4.28)$ & 57.1 & 0.05 & 0.63 & 5 & $1.40(1.14-1.70)$ & 18.6 & 0.30 & 0.88 \\
\hline No & 2 & $2.76(1.85-4.10)$ & 0 & 0.43 & & 2 & $1.36(1.04-1.78)$ & 0 & 0.92 & \\
\hline \multicolumn{11}{|c|}{ Prevalent coronary heart disease } \\
\hline Yes & 4 & $3.55(2.52-5.00)$ & 54.9 & 0.08 & 0.24 & 4 & $\begin{array}{l}1.40 \\
\quad(1.03-1.91) 1\end{array}$ & 38.9 & 0.18 & 0.98 \\
\hline No & 3 & $2.55(2.01-3.25)$ & 0 & 0.66 & & 3 & $1.38(1.15-1.66)$ & 0 & 0.98 & \\
\hline
\end{tabular}


Table 2 (continued)

\begin{tabular}{|c|c|c|c|c|c|c|c|c|c|c|}
\hline & \multicolumn{5}{|c|}{ Current Smoking } & \multicolumn{5}{|c|}{ Former smoking } \\
\hline & $n$ & $\mathrm{RR}(95 \% \mathrm{CI})$ & $I^{2}(\%)$ & $P_{\mathrm{h}}^{1}$ & $P_{\mathrm{h}}^{2}$ & $n$ & $\mathrm{RR}(95 \% \mathrm{CI})$ & $I^{2}(\%)$ & $P_{\mathrm{h}}^{1}$ & $P_{\mathrm{h}}^{2}$ \\
\hline \multicolumn{11}{|c|}{$Q T$ prolonging drug use } \\
\hline Yes & 4 & $3.55(2.52-5.00)$ & 54.9 & 0.08 & 0.24 & 4 & $1.40(1.03-1.91)$ & 38.9 & 0.18 & 0.98 \\
\hline No & 3 & $2.55(2.01-3.25)$ & 0 & 0.66 & & 3 & $1.38(1.15-1.66)$ & 0 & 0.98 & \\
\hline \multicolumn{11}{|l|}{ Digoxin } \\
\hline Yes & 4 & $3.55(2.52-5.00)$ & 54.9 & 0.08 & 0.24 & 4 & $1.40(1.03-1.91)$ & 38.9 & 0.18 & 0.98 \\
\hline No & 3 & $2.55(2.01-3.25)$ & 0 & 0.66 & & 3 & $1.38(1.15-1.66)$ & 0 & 0.98 & \\
\hline \multicolumn{11}{|l|}{ Physical activity } \\
\hline Yes & 6 & $3.18(2.49-4.05)$ & 46.6 & 0.10 & 0.46 & 6 & $1.38(1.19-1.60)$ & 0 & 0.42 & 0.97 \\
\hline \multirow[t]{3}{*}{ No } & 1 & $2.30(1.20-4.00)$ & & & & 1 & $1.40(0.80-2.90)$ & & & \\
\hline & & \multicolumn{9}{|c|}{ Ever smoking } \\
\hline & & $n$ & $\mathrm{RR}$ & $\% \mathrm{CI})$ & & & $I^{2}(\%)$ & $P_{\mathrm{h}}^{1}$ & & $P_{\mathrm{h}}^{2}$ \\
\hline All studies & & 7 & 2.01 & $.70-2.38)$ & & & 54.1 & 0.04 & & \\
\hline \multicolumn{11}{|l|}{ Follow-up } \\
\hline$<10$ years & & 3 & 2.57 & $.80-3.68)$ & & & 54.8 & 0.11 & & 0.04 \\
\hline$\geq 10$ years & & 4 & 1.78 & $.58-2.01)$ & & & 0 & 0.86 & & \\
\hline \multicolumn{11}{|l|}{ Sex } \\
\hline Men & & 1 & 1.82 & $.18-2.83)$ & & & & & & 0.47 \\
\hline Women & & 1 & 1.74 & $.44-2.10)$ & & & & & & \\
\hline Men and women & & 5 & 2.15 & $.69-2.72)$ & & & 64.3 & 0.02 & & \\
\hline \multicolumn{11}{|c|}{ Geographic location } \\
\hline Europe & & 6 & 2.09 & $.70-2.57)$ & & & 56.3 & 0.04 & & 0.49 \\
\hline America & & 1 & 1.74 & $.44-2.10)$ & & & & & & \\
\hline Asia & & 0 & & & & & & & & \\
\hline \multicolumn{11}{|l|}{ Number of cases } \\
\hline$<100$ & & 2 & 2.03 & $.29-3.21)$ & & & 69.5 & 0.07 & & 0.68 \\
\hline $100-<150$ & & 3 & 2.26 & $.54-3.32)$ & & & 70.7 & 0.03 & & \\
\hline$\geq 150$ & & 2 & 1.79 & $.53-2.09)$ & & & 0 & 0.58 & & \\
\hline \multicolumn{11}{|l|}{ Study quality } \\
\hline $0-3$ stars & & 0 & & & & & & & & 0.41 \\
\hline 4-6 stars & & 2 & 1.75 & $.47-2.08)$ & & & 0 & 0.85 & & \\
\hline $7-9$ stars & & 5 & 2.15 & $.69-2.72)$ & & & 64.3 & 0.02 & & \\
\hline \multicolumn{11}{|l|}{ Age } \\
\hline Yes & & 7 & 2.01 & $.70-2.38)$ & & & 54.1 & 0.04 & & $\mathrm{NC}$ \\
\hline No & & 0 & & & & & & & & \\
\hline \multicolumn{11}{|c|}{ Family history of CHD } \\
\hline Yes & & 1 & 1.74 & $.44-2.10)$ & & & & & & 0.49 \\
\hline No & & 6 & 2.09 & $.70-2.57)$ & & & 56.3 & 0.04 & & \\
\hline \multicolumn{11}{|l|}{ Alcohol } \\
\hline Yes & & 1 & 1.74 & $.44-2.10)$ & & & & & & 0.49 \\
\hline No & & 6 & 2.09 & $.70-2.57)$ & & & 56.3 & 0.04 & & \\
\hline \multicolumn{11}{|l|}{$B M I$} \\
\hline Yes & & 6 & 2.04 & $.69-2.46)$ & & & 61.6 & 0.02 & & 0.74 \\
\hline No & & 1 & 1.82 & $.18-2.83)$ & & & & & & \\
\hline \multicolumn{11}{|l|}{ Diabetes } \\
\hline Yes & & 5 & 2.15 & $.72-2.68)$ & & & 65.0 & 0.02 & & 0.35 \\
\hline No & & 2 & 1.70 & $.36-2.13)$ & & & 0 & 0.72 & & \\
\hline
\end{tabular}


Table 2 (continued)

\begin{tabular}{|c|c|c|c|c|c|}
\hline & \multicolumn{5}{|c|}{ Ever smoking } \\
\hline & $n$ & $\mathrm{RR}(95 \% \mathrm{CI})$ & $I^{2}(\%)$ & $P_{\mathrm{h}}^{1}$ & $P_{\mathrm{h}}^{2}$ \\
\hline \multicolumn{6}{|c|}{ Hypertension } \\
\hline Yes & 1 & $1.74(1.44-2.10)$ & & & 0.49 \\
\hline No & 6 & $2.09(1.70-2.57)$ & 56.3 & 0.04 & \\
\hline \multicolumn{6}{|c|}{ Blood cholesterol } \\
\hline Yes & 5 & $2.15(1.72-2.68)$ & 65.0 & 0.02 & 0.35 \\
\hline No & 2 & $1.70(1.36-2.13)$ & 0 & 0.72 & \\
\hline \multicolumn{6}{|c|}{ Prevalent coronary heart disease } \\
\hline Yes & 4 & $2.32(1.77-3.03)$ & 61.8 & 0.05 & 0.14 \\
\hline No & 3 & $1.72(1.49-1.99)$ & 0 & 0.93 & \\
\hline \multicolumn{6}{|c|}{$Q T$ prolonging drug use } \\
\hline Yes & 4 & $2.32(1.77-3.03)$ & 61.8 & 0.05 & 0.14 \\
\hline No & 3 & $1.72(1.49-1.99)$ & 0 & 0.93 & \\
\hline \multicolumn{6}{|c|}{ Digoxin } \\
\hline Yes & 4 & $2.32(1.77-3.03)$ & 61.8 & 0.05 & 0.14 \\
\hline No & 3 & $1.72(1.49-1.99)$ & 0 & 0.93 & \\
\hline \multicolumn{6}{|c|}{ Physical activity } \\
\hline Yes & 6 & $2.04(1.69-2.46)$ & 61.6 & 0.02 & 0.74 \\
\hline No & 1 & $1.82(1.18-2.83)$ & & & \\
\hline
\end{tabular}

$n$ denotes the number of studies

${ }^{1} \mathrm{P}$ for heterogeneity within each subgroup

${ }^{2} \mathrm{P}$ for heterogeneity between subgroups with meta-regression analysis

between smoking and risk of sudden cardiac death than any individual study. Our findings have important clinical and public health implications as cardiovascular diseases still is the leading cause of death worldwide, with coronary heart disease accounting for 8.9 million deaths globally in 2015 [1]. The current findings therefore provide further support for policies and interventions to prevent people from starting smoking in the first place and to aid smoking cessation among people who already smoke.

\section{Conclusion}

This meta-analysis found a threefold increase in the relative risk of sudden cardiac death among current smokers, and a $38 \%$ increase in risk in former smokers. Any further studies should aim to analyze in more detail the association between number of cigarettes per day, duration of smoking, and pack-years as well as duration of smoking cessation and sudden cardiac death. Nevertheless, the current findings strongly support interventions and policies to curb the tobacco epidemic.

Acknowledgements DA designed the research, conducted the literature search and analyses and wrote the first draft of the paper. DA and
SS conducted the screening of the literature search. All authors interpreted the data, revised the subsequent drafts for important intellectual content, read and approved the final manuscript. This work has been supported by funding from the Imperial College National Institute of Health Research (NIHR) Biomedical Research Centre (BRC) and the South-East Regional Health Authorities of Norway. The authors declare that there is no duality of interest associated with this manuscript. D. Aune takes responsibility for the integrity of the data and the accuracy of the data analysis.

Open Access This article is distributed under the terms of the Creative Commons Attribution 4.0 International License (http://crea tivecommons.org/licenses/by/4.0/), which permits unrestricted use, distribution, and reproduction in any medium, provided you give appropriate credit to the original author(s) and the source, provide a link to the Creative Commons license, and indicate if changes were made.

\section{References}

1. GBD 2015. Mortality and Causes of Death Collaborators. Global, regional, and national life expectancy, all-cause mortality, and cause-specific mortality for 249 causes of death, 1980-2015: a systematic analysis for the Global Burden of Disease Study 2015. Lancet. 2016;388(10053):1459-544.

2. Mehra R. Global public health problem of sudden cardiac death. J Electrocardiol. 2007;40(6 Suppl):S118-22.

3. Chugh SS, Reinier K, Teodorescu C, Evanado A, Kehr E, Al SM, Mariani R, Gunson K, Jui J. Epidemiology of sudden cardiac 
death: clinical and research implications. Prog Cardiovasc Dis. 2008;51(3):213-28.

4. Roger VL, Go AS, Lloyd-Jones DM, Adams RJ, Berry JD, Brown TM, Carnethon MR, Dai S, de Ford SG, Ford ES, Fox CS, Fullerton HJ, et al. Heart disease and stroke statistics-2011 update: a report from the American Heart Association. Circulation. 2011;123(4):e18-209.

5. Fishman GI, Chugh SS, Dimarco JP, Albert CM, Anderson ME, Bonow RO, Buxton AE, Chen PS, Estes M, Jouven X, Kwong R, Lathrop DA, et al. Sudden cardiac death prediction and prevention: report from a National Heart, Lung, and Blood Institute and Heart Rhythm Society Workshop. Circulation. 2010;122(22):2335-48.

6. Deo R, Albert CM. Epidemiology and genetics of sudden cardiac death. Circulation. 2012;125(4):620-37.

7. Nichol G, Thomas E, Callaway CW, Hedges J, Powell JL, Aufderheide TP, Rea T, Lowe R, Brown T, Dreyer J, Davis D, Idris A, et al. Regional variation in out-of-hospital cardiac arrest incidence and outcome. JAMA. 2008;300(12):1423-31.

8. Moss AJ, Zareba W, Hall WJ, Klein H, Wilber DJ, Cannom DS, Daubert JP, Higgins SL, Brown MW, Andrews ML. Prophylactic implantation of a defibrillator in patients with myocardial infarction and reduced ejection fraction. $\mathrm{N}$ Engl $\mathrm{J}$ Med. 2002;346(12):877-83.

9. Albert CM, Chae CU, Grodstein F, Rose LM, Rexrode KM, Ruskin JN, Stampfer MJ, Manson JE. Prospective study of sudden cardiac death among women in the United States. Circulation. 2003;107(16):2096-101.

10. de Vreede-Swagemakers JJ, Gorgels AP, Dubois-Arbouw WI, van Ree JW, Daemen MJ, Houben LG, Wellens HJ. Out-ofhospital cardiac arrest in the 1990's: a population-based study in the Maastricht area on incidence, characteristics and survival. J Am Coll Cardiol. 1997;30(6):1500-5.

11. Aune D, Sen A, O'Hartaigh B, Janszky I, Romundstad PR, Tonstad S, Vatten LJ. Resting heart rate and the risk of cardiovascular disease, total cancer, and all-cause mortality-a systematic review and dose-response meta-analysis of prospective studies. Nutr Metab Cardiovasc Dis. 2017;27(6):504-17.

12. Chiuve SE, Fung TT, Rexrode KM, Spiegelman D, Manson JE, Stampfer MJ, Albert CM. Adherence to a low-risk, healthy lifestyle and risk of sudden cardiac death among women. JAMA. 2011;306(1):62-9.

13. Jouven X, Desnos M, Guerot C, Ducimetiere P. Predicting sudden death in the population: the Paris Prospective Study I. Circulation. 1999;99(15):1978-83.

14. Wannamethee G, Shaper AG, Macfarlane PW, Walker M. Risk factors for sudden cardiac death in middle-aged British men. Circulation. 1995;91(6):1749-56.

15. Wen CP, Tsai SP, Chen CJ, Cheng TY. The mortality risks of smokers in Taiwan: part I: cause-specific mortality. Prev Med. 2004;39(3):528-35.

16. Wennberg P, Eliasson M, Hallmans G, Johansson L, Boman K, Jansson JH. The risk of myocardial infarction and sudden cardiac death amongst snuff users with or without a previous history of smoking. J Intern Med. 2007;262(3):360-7.

17. Sandhu RK, Jimenez MC, Chiuve SE, Fitzgerald KC, Kenfield SA, Tedrow UB, Albert CM. Smoking, smoking cessation, and risk of sudden cardiac death in women. Circ Arrhythm Electrophysiol. 2012;5(6):1091-7.

18. Lahtinen AM, Noseworthy PA, Havulinna AS, Jula A, Karhunen PJ, Kettunen J, Perola M, Kontula K, Newton-Cheh C, Salomaa V. Common genetic variants associated with sudden cardiac death: the FinSCDgen study. PLoS ONE. 2012;7(7):e41675.

19. Laukkanen JA, Makikallio TH, Rauramaa R, Kiviniemi V, Ronkainen K, Kurl S. Cardiorespiratory fitness is related to the risk of sudden cardiac death: a population-based follow-up study. J Am Coll Cardiol. 2010;56(18):1476-83.

20. Bertoia ML, Allison MA, Manson JE, Freiberg MS, Kuller LH, Solomon AJ, Limacher MC, Johnson KC, Curb JD, WassertheilSmoller S, Eaton CB. Risk factors for sudden cardiac death in post-menopausal women. J Am Coll Cardiol. 2012;60(25):2674-82.

21. Ohira T, Maruyama M, Imano H, Kitamura A, Kiyama M, Okada T, Maeda K, Yamagishi K, Noda H, Cui R, Masuda S, Kimura H, et al. Risk factors for sudden cardiac death among Japanese: the Circulatory Risk in Communities Study. J Hypertens. 2012;30(6):1137-43.

22. Karppi J, Laukkanen JA, Makikallio TH, Ronkainen K, Kurl S. Serum beta-carotene and the risk of sudden cardiac death in men: a population-based follow-up study. Atherosclerosis. 2013;226(1):172-7.

23. Deo R, Norby FL, Katz R, Sotoodehnia N, Adabag S, deFilippi CR, Kestenbaum B, Chen LY, Heckbert SR, Folsom AR, Kronmal RA, Konety S, et al. Development and validation of a sudden cardiac death prediction model for the general population. Circulation. 2016;134(11):806-16.

24. Stroup DF, Berlin JA, Morton SC, Olkin I, Williamson GD, Rennie D, Moher D, Becker BJ, Sipe TA, Thacker SB. Metaanalysis of observational studies in epidemiology: a proposal for reporting. Meta-analysis Of Observational Studies in Epidemiology (MOOSE) group. JAMA. 2000;283(15):2008-12.

25. Wells G, Shea B, O'Connell D., Peterson J, Welch V, Losos M, Tugwell P. The Newcastle-Ottawa Scale (NOS) for assessing the quality of nonrandomised studies in meta-analyses. http://www. ohri.ca/programs/clinical_epidemiology/oxford.asp. Accessed 15 Aug 2017.

26. DerSimonian R, Laird N. Meta-analysis in clinical trials. Control Clin Trials. 1986;7(3):177-88.

27. Higgins JP, Thompson SG. Quantifying heterogeneity in a metaanalysis. Stat Med. 2002;21(11):1539-58.

28. Egger M, Davey SG, Schneider M, Minder C. Bias in metaanalysis detected by a simple, graphical test. BMJ. 1997;315(7109):629-34.

29. Begg CB, Mazumdar M. Operating characteristics of a rank correlation test for publication bias. Biometrics. 1994;50(4):1088-101.

30. Agaku IT, King BA. Validation of self-reported smokeless tobacco use by measurement of serum cotinine concentration among US adults. Am J Epidemiol. 2014;180(7):749-54.

31. Pirie K, Peto R, Reeves GK, Green J, Beral V. The 21 st century hazards of smoking and benefits of stopping: a prospective study of one million women in the UK. Lancet. 2013;381(9861):133-41.

32. Goldenberg I, Moss AJ, McNitt S, Zareba W, Daubert JP, Hall WJ, Andrews ML. Cigarette smoking and the risk of supraventricular and ventricular tachyarrhythmias in high-risk cardiac patients with implantable cardioverter defibrillators. J Cardiovasc Electrophysiol. 2006;17(9):931-6.

33. Gheeraert PJ, De Buyzere ML, Taeymans YM, Gillebert TC, Henriques JP, De BG, De BD. Risk factors for primary ventricular fibrillation during acute myocardial infarction: a systematic review and meta-analysis. Eur Heart J. 2006;27(21):2499-510.

34. Plank B, Kutyifa V, Moss AJ, Huang DT, Ruwald AC, McNitt S, Polonsky B, Zareba W, Goldenberg I, Aktas MK. Smoking is associated with an increased risk of first and recurrent ventricular tachyarrhythmias in ischemic and nonischemic patients with mild heart failure: a MADIT-CRT substudy. Heart Rhythm. 2014;11(5):822-7.

35. Singh K. Effect of smoking on QT interval, QT dispersion and rate pressure product. Indian Heart J. 2004;56(2):140-2. 
36. D’Alessandro A, Boeckelmann I, Hammwhoner M, Goette A. Nicotine, cigarette smoking and cardiac arrhythmia: an overview. Eur J Prev Cardiol. 2012;19(3):297-305.

37. Zhu W, Yuan P, Shen Y, Wan R, Hong K. Association of smoking with the risk of incident atrial fibrillation: a meta-analysis of prospective studies. Int J Cardiol. 2016;1(218):259-66.

38. Chen LY, Sotoodehnia N, Buzkova P, Lopez FL, Yee LM, Heckbert SR, Prineas R, Soliman EZ, Adabag S, Konety S, Folsom AR, Siscovick D, et al. Atrial fibrillation and the risk of sudden cardiac death: the atherosclerosis risk in communities study and cardiovascular health study. JAMA Intern Med. 2013;173(1):29-35.

39. Pan A, Wang Y, Talaei M, Hu FB, Wu T. Relation of active, passive, and quitting smoking with incident type 2 diabetes: a systematic review and meta-analysis. Lancet Diabetes Endocrinol. 2015;3(12):958-67.
40. Bowman TS, Gaziano JM, Buring JE, Sesso HD. A prospective study of cigarette smoking and risk of incident hypertension in women. J Am Coll Cardiol. 2007;50(21):2085-92.

41. Halperin RO, Gaziano JM, Sesso HD. Smoking and the risk of incident hypertension in middle-aged and older men. Am J Hypertens. 2008;21(2):148-52.

42. Dochi M, Sakata K, Oishi M, Tanaka K, Kobayashi E, Suwazono Y. Smoking as an independent risk factor for hypertension: a 14-year longitudinal study in male Japanese workers. Tohoku J Exp Med. 2009;217(1):37-43.

43. Linneberg A, Jacobsen RK, Skaaby T, Taylor AE, Fluharty ME, Jeppesen JL, Bjorngaard JH, Asvold BO, Gabrielsen ME, Campbell A, Marioni RE, Kumari M, et al. Effect of smoking on blood pressure and resting heart rate: a mendelian randomization meta-analysis in the CARTA consortium. Circ Cardiovasc Genet. 2015;8(6):832-41. 